\title{
Interactive comment on "Differential
} photosynthetic response of marine planktonic and benthic diatoms to ultraviolet radiation under various temperature regimes" by Yaping Wu et al.

Anonymous Referee \#1

Received and published: 16 April 2017

The comment was uploaded in the form of a supplement:

http://www.biogeosciences-discuss.net/bg-2017-76/bg-2017-76-RC1-supplement.pdf

Interactive comment on Biogeosciences Discuss., doi:10.5194/bg-2017-76, 2017. 